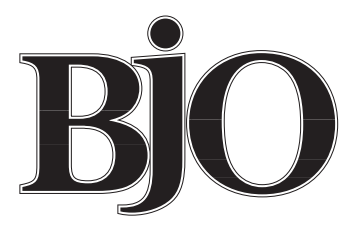

British Journal of Ophthalmology

\title{
Editorials
}

\section{Combination HIV therapy and opportunistic infections of the eye in people with AIDS}

The past 2 years have seen a dramatic improvement in the prognosis for people with HIV infection owing to the success of a strategy of using a combination of antiretroviral drugs to bring about a profound and durable suppression of viral replication. The drugs currently available all work through inhibiting key HIV specific enzymes-reverse transcriptase and HIV protease. The use of a three drug cocktail, usually consisting of two reverse transcriptase inhibitors (RTI) and one protease inhibitor (PI), has shown itself to be superior to single ${ }^{1}$ and dual $^{23}$ drug therapy in terms of the degree of viral suppression and also the ability to stall the development of resistance. ${ }^{4-7}$

HIV damages the immune system primarily by promoting the destruction of CD4 T lymphocytes, and this leaves the individual vulnerable to a greater number of infections as the cell numbers decline. Following the instigation of triple combination, highly active antiretroviral therapy, often called "HAART", most recipients experience a rise in blood CD4 $\mathrm{T}$ cell numbers, initially in the first month as a result of a release of cells from the reticuloendothelial system, and thereafter because of the production of new cells. ${ }^{89}$ This rise may occur even in people with quite advanced HIV related immunodeficiency and low CD4 counts. A reduction in the number of opportunistic infections, ${ }^{1011}$ including cytomegalovirus (CMV) retinitis, ${ }^{12} 13$ a reduction in the number of hospital admissions, ${ }^{14}$ and an improvement in the length ${ }^{15}$ and quality of life have all been shown to occur in the majority of recipients of HAART. Walsh et al have recently shown a dramatic increase in survival of AIDS patients with CMV retinitis who were treated with HAART. ${ }^{16}$

Before the era of combination antiretroviral therapy, most serious infections with CMV in HIV infected individuals occurred only once the CD4 $\mathrm{T}$ lymphocyte count fell below $100 \times 10^{6} / 1$. Clearly, with the use of combination therapy in those whose CD 4 count never falls below 100, there should be no risk of CMV. Those who start combination therapy with CD 4 counts below $100 \times 10^{6} / 1$ may be vulnerable to CMV disease until their immune system recovers sufficiently. When the point of immunocompetence to CMV is regained is something we are unable to measure at present. This is of even more significance in those AIDS patients with existing CMV disease who start HAART and experience an improvement in immune function that may at some point make it unnecessary for them to continue maintenance anti-CMV treatment (which is often toxic, inconvenient, and expensive). ${ }^{17}{ }^{18}$

Van den Horn et al report in this issue of BfO (p 988) on 15 patients with AIDS related CMV retinitis, who were receiving maintenance therapy with anti-CMV drugs, and who, as would be expected, had very low CD4 T lymphocyte counts. They document the recurrence rate of CMV retinitis in these patients after receiving combination therapy including a protease inhibitor. Recurrences occurred in seven patients all of whom had failed to achieve a rise in their CD4 lymphocyte count above $100 \times 10^{6} / 1$. Those patients who successfully obtained CD 4 counts above $100 \times 10^{6} / 1$ did not suffer any recurrence of CMV retinitis, and one might speculate that it may be safe for those individuals to stop maintenance anti-CMV therapy.

Paradoxically, the improvement in immune function that follows the instigation of HAART may have its drawbacks. Some patients with CD4 T lymphocyte counts below $50-100 \times 10^{6} / 1$ may have hitherto unrecognised and asymptomatic infection with $\mathrm{CMV}$ retinitis. As immune function returns, so there is an increased inflammatory response which, in the case of CMV retinitis, results in visual loss and an abnormal funduscopic appearance, often quite different from the classic "pizza pie" or "ketchup and scrambled egg" appearances of CMV retinitis. ${ }^{19} 20$

The practice of the ophthalmologist looking after people with HIV has changed. The widespread use of HAART has reduced the incidence of CMV retinitis and indeed other opportunistic infections of the eye. ${ }^{21}$ The enhanced immune function that follows the commencement of HAART may produce unexpected appearances of retinitis with severe inflammation. ${ }^{22}$ Anti-CMV maintenance therapy may now be necessary only for a few months until immune restoration has occurred, ${ }^{23}$ but specific tests to gauge an individual's cell mediated immune function against CMV would be useful to tell when this time has been reached. Additionally, some of the drugs used in the HAART combination may have ophthalmic side effects.

One fear is that the effects of HAART will be temporary, lasting perhaps only a few years, after which we may see CMV retinitis and other opportunistic infections becoming commonplace again.

STEPHEN ASH

The Pasteur Suite, Ealing Hospital, Uxbridge Road, Southall, Middlesex UB1 $3 \mathrm{HW}$ 
1 Fischl MA, Richman DD, Grieco $\mathrm{MH}$, et al. The efficacy of azidothymidine AZT) in the treatment of patients with AIDS and AIDS-related complex: a double-blind, placebo-controlled trial. N Engl F Med 1987;317:185-91.

2 Delta Coordinating Committee. Delta: a randomised double-blind controlled trial comparing combinations of zidovudine plus didanosine or zalcitabine with zidovudine alone in HIV infected individuals. Lancet 1996; 348:283-91.

3 Saravolatz LD, Windslow DL, Collins G, et al. Zidovudine alone or in combination with didanosine or zalcitabine in HIV-infected patients with the acquired immunodeficiency syndrome or fewer than 200 CD4+ cells per cubic millimeter. N Engl F Med 1996;335:1099-106.

4 Squires K, Gulick R, Santane J, et al. An open-label, randomized, comparative study of $\mathrm{d} 4 \mathrm{~T}+3 \mathrm{TC}+\mathrm{IDV}$ versus $\mathrm{ZDV}+3 \mathrm{TC}+\mathrm{IDV}$ in treatment naive HIV-infected patients. START 1. 5th Conference on Retroviruses and Opportunistic Infections, Chicago, 1998 (abstract 380).

5 Eron J, Peterson D, Murphy R, et al. An open-labelled, randomized, comparative study of $\mathrm{d} 4 \mathrm{~T}+\mathrm{ddI}+\mathrm{IDV}$ versus $\mathrm{ZDV}+3 \mathrm{TC}+\mathrm{IDV}$ in treatment naive HIV-infected patients. START 2.5th Conference on Retroviruses naive HIV-infected patients. START 2. 5th Conference on
and Opportunistic Infections, Chicago, 1998 (abstract 381).

6 Notermans DW, de Wolf F, Foudraine NA, et al. The effects of an antiretroviral triple combination with ritonavir, AZT, and 3TC. 3rd International Congress on Drug Therapy in HIV Infection, Birmingham, 1996;10: Congress on Drug

7 Gulick RM, Mellors J, Havlir D, et al. Potent and sustained antiretroviral activity of indinavir, zidovudine and lamivudine. XIth International Conference on AIDS, Vancouver, 1996; abstract Th.B.931

8 Connors M, Kovacs JA, Krevat S, et al. HIV infection induces changes in CD4+ T-cell phenotype and depletions within the CD4+ T-cell repertoire that are not immediately restored by antiviral or immune-based therapies. Nat Med 1997;3:533-40.

9 Miedema F, Pakker NG, Notermans DW, et al. Immunological reconstitution after triple combination therapy in HIV-1 infection: a composite of redistribution and proliferation. 5th Conference on Retroviruses and Opportunistic Infections, Chicago, 1998; abstract 20.

10 Forrest DM, Seminari E, Montaner JSG, et al. Changing incidence and spectrum of AIDS-defining illnesses in the modern antiretroviral era. 5th Conference on Retroviruses and Opportunistic Infections, Chicago, 1998; abstract 179 .
11 Michaels S, Clark R, Kissinger P. Differences in the incidence rate of opportunistic processes before and after the availability of protease inhibitors. 5 th Conference on Retroviruses and Opportunistic Infections, Chicago, 1998; abstract 180 .

12 Gerard M, Postelmans L, De Wit S, et al. Impact of protease inhibitors on the incidence of recurrent CMV retinitis. 5th Conference on Retroviruses and Opportunistic Infections, Chicago, 1998; abstract 758

13 Moore RD, Keruly JC, Chaisson RE. Decline in CMV and other opportunistic disease with combination antiretroviral therapy. 5th Conference on Retroviruses and Opportunistic Infections, Chicago, 1998; abstract 184.

14 Mouton Y, Alfandari S, Valette M, et al. Impact of protease inhibitors on AIDS-defining events and hospitalizations in 10 French AIDS reference centres. AIDS 1997;11:101.

15 Hogg RS, O'Shaughnessy MV, Gataric N, et al. Decline in deaths from AIDS due to new antiretrovirals (letter). Lancet 1997;349:1294.

16 Walsh JC, Jones CD, Barnes EA, et al. Increasing survival in AIDS patients with cytomegalovirus retinitis treated with combination antiretroviral therapy including protease inhibitors. AIDS 1998;12:613-18.

17 Whitcup SM, Fortin E, Muccioli C, et al. Therapeutic effect of increased CD4 T-cell counts on cytomegalovirus retinitis in patients with AIDS. FAMA 1997;277:1519-20.

18 Reed JB, Schwab IR, Gordon J, et al. Regression of cytomegalovirus retinitis associated with protease-inhibitor treatment in patients with AIDS. Am $\mathcal{F}$ Ophthalmol 1997;124:199-205.

19 Zegans ME, Walton RC, Holland GN, et al. Transient vitreous inflammatory reactions associated with combination antiretroviral therapy in patients with AIDS. Am F Ophthalmol 1998;25:292-300.

20 Jacobson MA, Zegansm, Pavan PR, et al. Cytomegalovirus retinitis after initiation of highly active antiretroviral therapy. Lancet 1997;349:1443-5.

21 Freeman WR, MacDonald JC, Torriani FJ, et al. 5th Conference on Retroviruses and Opportunistic Infections, Chicago, 1998; abstract 757.

22 Nussenblatt RB, Lane HC. Human immunodeficiency virus disease: changing patterns of intraocular inflammation. Am f Ophthalmol 1998;125:37482 .

23 Torriani FJ, Havlir DV, Freeman WR, et al. Proliferative responses against CMV in AIDS patients on HAART and with healed CMV retinitis who stopped maintenance therapy. 5th Conference on Retroviruses and Opportunistic Infections, Chicago, 1998; abstract 747 .

\section{Seeing beyond acuity}

What are the effects of uniocular disorders on visual outcome? Are some treatment strategies more effective than others? Has the good eye been compromised? Does the age of onset matter? What is the influence of deprivation versus abnormal competition between an affected eye and a fellow good eye? These are all important questions. In answering these questions, we often turn primarily to the "gold standard"-Snellen acuity. But good vision involves more than being able to decipher small details at high contrast. It also involves sensitivity to objects of low contrast, stereopsis, being able to accurately align easily visible objects, the perception of motion, and a host of other aspects of vision. Studies of animals indicate that some aspects of vision are more susceptible to abnormal visual input than others and that the sensitive period differs for different aspects of vision. ${ }^{1}$ Thus, a clear understanding of visual outcome requires the assessment of more than just visual acuity.

Patients with strabismic amblyopia, for example, have a variety of deficits in the amblyopic eye and often have similar but milder deficits in the dominant eye. Motor deficits include irregular tracking of moving objects, ${ }^{2-5}$ eccentric fixation and/or unsteady fixation, ${ }^{36-8}$ and asymmetrical optokinetic nystagmus (OKN) such that OKN, when tested monocularly, can be elicited easily when a repetitive pattern moves from the temporal visual field towards the nasal visual field but not when it moves in the opposite direction. ${ }^{9-11}$ Sensory deficits include not only reduced acuity, but also abnormal scotopic sensitivity, ${ }^{12}$ reduced contrast sensitivity especially at high spatial frequencies, ${ }^{13-15}$ difficulty in aligning stimuli accurately even when they are well above threshold, ${ }^{16-18}$ and reports of distorted perception in the amblyopic eye. ${ }^{19}$

Strabismic amblyopes also show deficits in their perception of motion. They judge temporalward motion to be slower than nasalward motion of the same speed, especially at slow velocities ${ }^{20-22}$; they are poor at identifying form from motion defined cues $^{23}$; and they sometimes show deficits in perceiving the direction of motion. ${ }^{9}$

In this issue of the journal ( $p$ 991), Kelly and Buckingham identify another abnormality of motion perception in childhood amblyopia. Children aged 5-71/2 years, most of whom had strabismic amblyopia, were asked to identify which of two vertical bars was oscillating. A staircase procedure was used to determine the minimum amount of horizontal oscillation that could be detected reliably (coined as the "oscillatory movement displacement threshold"). Overall, thresholds in the amblyopic eyes were almost $50 \%$ worse than in the dominant eyes, which were the same as those of children with normal vision. When patients were divided into those with no stereopsis versus those with at least gross stereopsis, only those with no stereopsis, and hence those with the greatest imbalance of interocular competition, showed significantly elevated thresholds for detecting oscillatory movement with their amblyopic eye.

The article by Kelly and Buckingham raises several issues for further consideration. Firstly, the results from normal children were correlated with age at the time of the test. In fact, a previous article by these same authors testing oscillatory thresholds in large groups of normal children and adults showed that thresholds improve by $64 \%$ between 5 and $71 / 2$ years of age and do not reach adult values until after 8 years of age. ${ }^{24}$ Thus, it would be interesting to calculate the ratio of each patient's threshold in the amblyopic eye to that of age matched normals. The size of the threshold elevation relative to normal could then be correlated with the age of onset of strabismus in an attempt to identify the sensitive period. Only when strabismus begins before 2 years of age do patients show abnormalities 
in visually evoked potentials to oscillating motion, ${ }^{25}{ }^{26}$ in perceiving the direction of motion, ${ }^{9}$ and in the symmetry of OKN. ${ }^{9}{ }^{10}$ The same may be true for oscillatory movement thresholds. Secondly, it is surprising that oscillatory thresholds were normal in the dominant eye, especially since subtle deficits have been reported for many aspects of vision, including other measures of the integrity of motion processing. ${ }^{9-11}$ Perhaps an analysis of thresholds like the one suggested above for the amblyopic eye would reveal subtle deficits in the dominant eye after early onset strabismus. Thirdly, it would be useful to separate the results for strabismic versus anisometropic amblyopes since, at least on some tasks, the two groups perform differently ${ }^{17}$ and are thought to have different underlying neural deficits. ${ }^{27-29}$ None the less, the study by Kelly and Buckingham adds to our understanding of amblyopia, an understanding that goes far beyond that achievable from only traditional clinical measures of visual outcome.

Thanks to Drs Daphne Maurer and Henry Brent for comments on an earlier draft.

TERRI L LEWIS

Department of Ophthalmology, The Hospital for Sick Children and University of Toronto, 555 University Avenue, Toronto, Ontario, Canada, M5G 1 X8

1 Harwerth RS, Smith EL III, Duncan GC, et al. Multiple sensitive periods in the development of the primate visual system. Science 1986;232:235-8.

2 Bedell HE, Yap YL, Flom MC. Fixational drift and nasal-temporal pursuit Bedell HE, Yap YL, Flom MC. Fixational drift and nasal-temporal pursuit
asymmetries in strabismic amblyopes. Invest Ophthalmol Vis Sci 1990;31: asymmet

3 Fukai S, Tsutsui J, Nakayama Y. Abnormal pursuit movements of the fellow eye in amblyopia with strabismus. In: Moore S, Mein J, Stockbridge L, eds. Orthoptics, past, present, future. Trans 3rd International Orthoptic Congress, Boston, July 1975. New York: Stratton, 1976;75-91.

4 Tychsen L, Hurtig RR, Scott WE. Pursuit is impaired but the vestibulo-ocular reflex is normal in infantile strabismus. Arch Ophthalmol 1985;103:536-9.

5 Von Noorden GK, Mackensen G. Pursuit movements of normal and amblyopic eyes. An electro-ophthalmographic study. II. Pursuit movements in amblyopic patients. Am F Ophthalmol 1962;53:477-87.

6 Hermann JS, Priestley BS. Bifoveal instability. The relationship to strabismic amblyopia. Am f Ophthalmol 1965;60:452-9.
7 Kandel GL, Grattan PE, Bedell HE. Monocular fixation and acuity in

amblyopic and normal eyes. Am J Optom Physiol Opt 1977;54:598-608.
8 Srebro R. Measurements of eccentricity of fixation in normals and in Srebro R. Measurements of eccentricity of fixation in normal
amblyopes by evoked potentials. Vision Res 1983;23:1527-32.

9 Fawcett S, Raymond JE, Astle WF, et al. Anomalies of motion perception in infantile esotropia. Invest Ophthalmol Vis Sci 1998;39:724-35.

10 Reed MJ, Steinbach MJ, Anstis SM, et al. The development of optokinetic nystagmus in strabismic and monocularly enucleated subjects. Behav Brain Res 1991;46:31-42.

11 Schor CM, Fusaro RE, Wilson N, et al. Prediction of early-onset esotropia from components of the infantile squint syndrome. Invest Ophthalmol Vis Sci 1997;38:719-40.

12 Kandel GL, Bedell HE, Fallon JH. Near-final scotopic thresholds in normal eyes and in the dominant eyes of amblyopes. Ophthalmic Res 1976;8:42533.

13 Hess RF, Howell ER. The threshold contrast sensitivity deficit in strabismic amblyopia: evidence for a two type classification. Vision Res 1977;17:104955

14 Levi DM, Harwerth RS. Spatio-temporal interactions in anisometropic and strabismic amblyopia. Invest Ophthalmol Vis Sci 1977;16:90-5.

15 Leguire LE, Rogers GL, Bremer DL. Amblyopia: the normal eye is not normal. F Pediatr Ophthalmol Strabismus 1990;27:32-8.

16 Bedell HE, Flom MC, Barbeito R. Spatial aberrations and acuity in strabismus and amblyopia. Invest Ophthalmol Vis Sci 1985;26:909-16.

17 Hess RF, Holliday IE. The spatial localization deficit in amblyopia. Vision Res 1992;32:1319-39.

18 Levi DM, Klein SA. Vernier acuity, crowding, and amblyopia. Vision Res 1985;25:979-91.

19 Sireteanu R, Lagreze W-D, Constantinescu DH. Distortions in twodimensional visual space perception in strabismic amblyopia. Vision Res 1993;33:677-90

20 Roberts N, Westall C. OKN asymmetries in amblyopia - their effect on velocity perception. Clin Vis Sci 1990;5:383-9.

21 Tychsen L, Lisberger SG. Maldevelopment of visual motion processing in humans who had strabismus with onset in infancy. F Neurosci 1986;6:2495508.

22 Tychsen L, Rasteli A, Steinman S, et al. Biases of motion perception revealed by reversing gratings in humans who had infantile-onset strabismus. Dev Med Child Neurol 1996;38:408-22.

23 Giaschi DE, Regan D, Kraft S, et al. Defective processing of motion defined form in the fellow eye of patients with unilateral amblyopia. Invest Ophthalform in the fellow eye of pater

24 Buckingham TJ, Kelly SL. The comparative development of movement hyperacuity and visual acuity in children. Vision Res 1996;36:3851-6.

25 Norcia AM, Garcia H, Humphry R, et al. Anomalous motion VEPs in infants and in infantile esotropia. Invest Ophthalmol Vis Sci 1991;32:436-9.

26 Norcia AM, Jampolsky A, Hamer R, et al. Plasticity of human motion processing following strabismus surgery. Invest Ophthalmol Vis Sci 1991;32: 1044 (abstract).

27 Hess RF, Field D. Is the spatial deficit in strabismic amblyopia due to loss of cells or an uncalibrated disarray of cells? Vision Res 1994;34:3397-406.

28 Levi DM, Klein SA. Sampling in spatial vision. Nature 1986;320:360-2.

29 Levi DM, Klein SA. Limitations on position coding imposed by undersampling and univariance. Vision Res 1996;36:2111-20. 